\title{
The Assessment of Psychiatric Disorders in Intellectual Disability: The State of the Art
}

\author{
Marco O. Bertelli ${ }^{1,}$, Michele Rossi ${ }^{1}$, Daniela Scuticchio ${ }^{1}$, Annamaria Bianco ${ }^{1}$ and \\ Luana Salerno ${ }^{1,2}$
}

${ }^{1}$ CREA (Research and Clinical Center), San Sebastiano Foundation, Misericordia di Firenze, Florence, Italy

${ }^{2}$ INS (Institute of Neurosciences), Florence, Italy

\begin{abstract}
Intellectual Disability (ID) represents a meta-syndromic group of several different conditions, each one with specific cognitive and communication features. This constitutes one the main reason for which the diagnosis of psychiatric disorders in adults with ID is challenging. The aim of this paper is to provide a comprehensive and updated state of art on the assessment of psychiatric disorders in people with ID. In order to accomplish this goal, authors performed a systematic literature mapping trying to answer to the following questions: what are the issues in the psychiatric diagnostic process for adults with ID? What methods and procedures have been used for psychiatric assessment in ID? To date, is it possible to identify the most effective diagnostic procedures?

Results indicated that the main critical issues in the psychiatric diagnostic process were the following: the identification of psychiatric symptoms, the behavioural equivalents, the diagnostic criteria, the setting, the source of information, the screening and diagnostic instruments. An increasing interest in screening instruments for providing appropriate diagnosis for people with ID has been noted in the recent years. For this reason, available assessment tools have been briefly indicated, with their strengths and weaknesses. Although the recent advances, more research is needed in order to increase diagnostic accuracy in this heterogeneous group of patients.
\end{abstract}

Keywords: Intellectual disability, psychiatric disorders, psychopathology, assessment, diagnosis, tools.

\section{INTRODUCTION}

People with Intellectual Disability (PwID) present a high vulnerability to develop mental health problems. It has been reported that they are up to four times likely to develop a mental disorder than the general population [1]. The point prevalence is about $50 \%$, even in vocational settings with psychological support [2], and the annual incidence is about $8 \%$ [3]. 25-44\% of PwID has at least one psychiatric disorder [1], 21\% has two, and $8 \%$ has three [4], with the most common diagnostic category being that of autism spectrum disorders, followed by mood disorders and anxiety disorders [1].

Generally, causes underlying this vulnerability are not the same of those determining the ID condition. In fact, there is evidence that they are the result of a combination of biological, psychological and social factors [5].

For a long time, it was believed that psychiatric disorders (PD) could not occur in PwID. This could be due to a lack of consensus on what conditions in ID should be considered as mental health problems [6], but also for the difficulty in adapting current diagnostic criteria to PwID. Therefore, PwID have a different way

*Address correspondence to this author at the CREA Research and Clinical Center, San Sebastiano Foundation, Misericordia di Firenze, Firenze, Italy;

Tel: +39 055 7392880; E-mail: mbertelli@crea-sansebastiano.org to perceive and to communicate respect to the nonintellectually disabled population. They are constantly exposed to many stressors, and present impairment of personal functioning, varying with the severity of the disability.

For all these reasons, the diagnostic assessment of PD should be appropriately modified and adjusted in this specific population for the cognitive dysfunctions, language and communication limitations, sensory impairments, skill deficits, adaptations difficulties, and physical disabilities often present in PwID. Moreover, it has also been reported a frequent interference of problem behaviours (PBs), ranging between 5 and $60 \%$ [7], in the psychiatric diagnostic process $[8,9]$. In some cases these PBs seem to be determined by genetic causes expressed in specific behavioural phenotypes [10], whereas in other cases they appear as the result of a complex etiopathogenesis of bio-psycho-social factors [11].

The long-lasting neglect of the presence of PD in PwID was a major impediment to research on the specific psychopathological phenomenology of ID, but also to the development of effective assessment procedures. Given these issues, it is unsurprising that clinicians have generally difficulties in diagnosing PD in PwID, if they are not specifically trained [12]. Moreover, it has been suggested that the negative attitude held by some professional caregivers towards mental health 
services for PwID [13] is likely a consequence of that negative cultural background. However, it is widely agreed that both knowledge and attitude may be enhanced through adequate training [14-16,12]. In the last twenty-five years many professionals have increasingly been working on these issues and considerable knowledge is now available on psychiatric presentation, assessment procedure, and tools for ID. Notwithstanding, implementations of acquired knowledge for clinical activity are still lacking.

In this context, we aim to provide an updated state of art of literature regarding the diagnostic assessment of PD in PwID.

\section{MATERIALS AND METHODS}

Methodology used was a systematic mapping, that varies from a systematic review in the breadth of the topic area and questions, and the limits of data extracted [17].

Authors reviewed the international literature on the basis of the following questions: what are the issues in the psychiatric diagnostic process for adults with ID? What methods and procedures have been used for psychiatric assessment in ID? To date, is it possible to identify the most effective procedures?

The literature search was performed through MEDLINE, Medmatrix, NHS Evidence, Web of Science, and Cochrane Library databases. For MEDLINE, the following search string were used: ("intellectual disab*" or "mental retard*" or "learning disab*") and ("psychiatric disorders" or "psychopathology" or "mental health") and (assessment or diagnosis or procedure or tool or evaluation). For the other databases some minor adaptations have been used. The literature search was conducted in April 2015.

The titles and abstract of identified papers were screened. Exclusion criteria were studies not considering human and adult population, and not published in English language. Articles so filtered were read in full and examined according to their capability in answering the reference questions.

Titles and abstracts were checked by two researchers, both clinical psychologists working in the field of ID and specifically trained for the research purpose. Their agreement concordance was based on the first $10 \%$ of identified material, and resulted of $99.4 \%$.
Full articles were then read by the two psychologists, and also by two psychiatrists with some expertise in ID. The agreement rate between evaluators was calculated by comparing the number of paragraphs per article judged as responding to the mapping questions. Again, the concordance on the first 15 articles resulted very high (98.7\%).

\section{RESULTS}

We found 2118 articles matching keywords. After the title and abstract checking, only 422 were considered eligible and relevant to the research questions. Among them, 26 were excluded because of language and 326 because of lack of relevance.

After full article reading only 41 papers resulted to be really pertinent to our mapping.

Data analysis showed the following critical issues in diagnosing psychiatric disorders in adults with ID: identification of psychiatric symptoms, behavioural equivalents, diagnostic criteria, setting, source of information, screening and diagnostic tools.

The mapping of the most recent literature also allowed to identify some of the most effective assessment procedures and tools, and their utility according to the level of impairment in cognitive and personal skills. The key-points identified by the mapping for psychiatric assessment in PwID in daily clinical practice are the following: source and reason for referral, documentation of confidentiality, demographic details, family history, personal history with emphasis on development and education, medical and psychiatric history, history of problem behaviours, Forensic or offending history, life events, relationships and sexual history, substance misuse history, training and vocational record, previous pharmacological and non-pharmacological treatments, physical examination (with particular attention to be put on neurological signs and symptoms), psychiatric examination, assessment of psychological factors, assessment of social ecologies, assessment of risks to self and others, as well as risk of self-neglect, abuse and exploitation, clinical investigations, and psychodiagnostic screening tools.

\section{Presentation of Psychiatric Symptoms}

The first critical issue found through the literature examination, is represented by the "diagnostic overshadowing", which is a difficulty in attributing the observed or referred dysfunctions and behavioural 
alterations to the basic condition of ID or to a cooccurrent PD [8,9,18-20]. Other identified factors appear to be linked to the presentation of symptoms, that is often atypical, chaotic, intermittent, fluctuating, masked, mixed, or poorly defined.

The developmental level, the previous life experiences, interpersonal, cultural, and environmental influences have been reported by Sovner $[21,22]$ and Bouras [23] as factors determining a considerable impact on the form of psychopathology. Moreover, deficits in abstract thinking can limit introspection capacity and determine difficulties in recognizing emotional symptoms, in defining one's own life experiences and in communicating states of suffering [24]. This is what Sovner [21,22] defined as "intellectual distortion".

People with more severe ID are often passive and compliant, because of a low ability to tolerate stress generating a consequent anxiety-induced decompensation $[21,22]$.

They tend to express their psychic suffering through behavioural changes, including the increase of severity or frequency of chronic maladaptive behaviour (baseline exaggeration effect) $[21,22,25,26]$. In this perspective, an accurate baseline of previous functioning, abilities and behaviours constitutes a fundamental step in detecting signals of onset of a cooccurrent psychiatric disorder $[21,22]$.

It is important to note that the poor verbal expression abilities, the impoverished social skills and the characteristic life experiences may also produce the so-called "psychosocial masking" [21,22], contributing to the complexity of diagnostic assessment of comorbid PD.

Lastly, an additional aspect that strongly characterizes the psychiatric symptomatology in PwID is the neurovegetative vulnerability: pains, organ dysfunction, changes in circadian rhythms, dystonia of the autonomic nervous system are frequently the main expression of emotional dysregulation [27].

It is difficult determining if problem behaviours (PBs) are the result of organic conditions, co-occurrent PDs, environmental influences, or a combination of all these conditions. In fact, the same behaviour can be differently interpreted by the clinicians, even in the same staff. Obviously, this generates relevant implications for intervention.
Some studies demonstrated a relationship between PBs and PD [28-31, 26, 32], particularly strong in individuals with a lower level of functioning [29], and some behavioural equivalents have been identified for specific symptoms [33]. Charlot [34] suggested to consider principally the course of the behaviour, respect to other symptoms of a PD, in order to decide if the behaviour could be considered as a symptom equivalent. However, whereas some studies found no evidence on PBs as behavioural equivalents of PD [35], others indicated that PBs and maladaptive behaviours should be interpreted as nonspecific indicators of emotional distress, rather than atypical symptoms [36].

Several researchers have emphasised the difficulties of using psychiatric diagnostic criteria designed for the general population on PwID. It has been proposed that these criteria may be used without adaptation only in few subjects with borderline to mild ID [37], but not in people with more severe ID $[21,22,38]$.

The currently used standard diagnostic manuals, such as DSM-IV-TR, DSM-5, and ICD-10 [39-41], present many issues that may interfere with diagnostic reliability. Firstly, the majority of diagnostic criteria rely on verbal items and/or descriptions of emotional, behavioral or psychological events that are difficult to understand or describe to most PwID. Secondly, the standard criteria were not developed for using thirdparty information and the interpretation of overt behaviours, that are quite common in PwID because of their lack of verbal skills. Thirdly, several diagnostic categories in the standard manuals have an extensive use of sub-categorisation, assuming the presence of detailed and reliable information on the psychopathology that does not apply to PwID [24]. Finally, it is not clarified how behavioral problems commonly found in PwID should be classified within the ICD-10 or DSM-IV-TR or DSM-5 schemes.

A variety of modifications of the standard diagnostic systems have been proposed for PwID [42-48]. Adaptations of the ICD-10 and DSM-IV-TR have been respectively produced by the Royal College of Psychiatrists (UK) and the National Association for Dual Diagnosis (USA), with the names of Diagnostic Criteria for Learning Disability (DC-LD) [49] and Diagnostic Manual - Intellectual Disability (DM-ID) [48] Although they need some improvements, these manuals provide a valuable clinical utility, helping the clinician to better recognize the psychiatric 
symptomatology in PwID. Data from a 2006's survey in the United States of America performed on 63 clinicians and 845 patients with ID, showed that DM-ID was simple to use. It allowed an appropriate and more specific diagnosis in comparison to the DSM-IV-TR, and a less frequent use of "not otherwise specified" (NOS) categories [51]. These findings are in line with what reported by Cooper and collaborators [1] on the prevalence variation of PD according to the diagnostic criteria used. Such data showed a prevalence rate of $52.2 \%$ if diagnosis was made only on the basis of clinical judgment, of $45.1 \%$ if the diagnosis was based on DC-LD, of $11.4 \%$ using the DSM-IV-TR criteria, and of $10.9 \%$ using the Diagnostic Criteria for Research of the International Classification of mental and behavioral disorders - 10th edition (DCR-ICD-10) [41]. It is worth to note that the DC-LD include an attempt to use behavioral equivalents for verbal descriptions [52], and further study and research have been conducted in order to produce more reliable conversion for the forthcoming DC-LD 2. Also an update of the DM-ID is under process for about 18 months by an international task force of expert clinicians, for adapting the measure to the new DSM- 5 criteria.

\section{Assessment Procedure}

The assessment in this kind of population requires flexibility in the setting as well in its duration. Generally, it is preferable choosing as setting the daily life environment of the subject. Therefore, the evaluation on site reduces the risk that environmental factors impact on and adversely influence the psychic conditions and behaviors. The clinician should use simple and unambiguous language, avoiding metaphors and idioms. Moreover, because PwID are suggestible and acquiescent, it is recommended to avoid also leading and repetitive questions, preferring instead multiple-choice ones or questions formulated in several and different manners, including contradictions. The use of picture and symbols should be also preferred.

The assessment should be performed by a multiprofessional equipe, because it may enhance the validity of the diagnostic process. This equipe should include a psychiatrist, a clinical psychologist, a nurse, a general practitioner, and other specialised therapists working with the subject under evaluation.

The reliability of the information source, including the same individuals with ID being assessed, is often uncertain. Some features of PD, such as sense of hopelessness or worthlessness, suicidal ideation, delusional perception are very complex to evaluate, requiring a high level of expressive language, abstract thinking, conceptualization, memory and selfawareness. For these reasons, it is very difficult to detect them in PwID, particularly in the most severe cases [27].

Direct interviews are problematic also because of the frequent difficulty of PwID to understand the task demands in testing situations [53]. Additionally, it can be very challenging for PwID to recognize that they need help and depend on others to identify the meaning of some changes. People with borderline intellectual functioning or mild ID seem to be quite able to describe their own behaviours and feelings $[54,55,19]$. However, even in these cases, some features linked to the cognitive impairment, such as suggestibility, acquiescence, attention deficit, trouble with temporal sequencing, or distractibility, may adversely affect the attempt to provide a full account of their own feelings and experiences.

Obtaining information by 'a significant other' on the onset of psychiatric symptoms is particularly useful in clinical practice with PwID. Nevertheless, it is important to note that also what others report can be characterized by many troublesome issues. In the first place, the indirect or atypical presentation of symptoms often limits the capability of identify them for caregivers or other proxies $[56,27]$. Secondly, because it is a widespread belief that all problems of PwID are inevitable and unchangeable [27,9], family members have difficulties to believe that the person with ID may suffer from mental health problems. Consequently, they tend to deny the presence of psychiatric symptoms, or try to project their own thoughts and interpretation of symptoms and behaviours, and may alter information about the symptoms that could be distressing for the subject with ID.

Literature reports that proxy evaluation may vary depending on a number of factors, ranging from the cultural level and other personal characteristics to the specific nature of the relationship and involvement $[57,58]$. The accuracy of the ratings depends heavily on the experience and insight of the informant, as well as on how well he/she knows the person being rated. The literature mapping identified a gap in the research comparing the degree of agreement or disparity between ratings made through different informants [59]. The integration of different sources of information, such as familiars, carers, or other proxies is highly 
recommended to measure any significant behavioural change that has occurred, to interpret it as symptom equivalent, and to increase the validity of the psychiatric assessment.

Research to date shows that PD were diagnosed only in a few studies through the examination of case registers [19], and clinical records were frequently incomplete or incorrect. Traditionally, the assessment has used one of the three following methodologies: ratings by a significant other, a clinical interview or selfreport. Bramston and Fogarty [55] found that the degree of agreement among these three methods is consistently low, although limited concordance was found between self-report and clinical interview. For example, Benson and Ivins [60] found that informants consistently rated higher levels of symptoms, such as anger, than those reported by participants themselves.

Taken together, this findings indicates that the best way to assess PD in PwID is the use of a comprehensive diagnostic system including self-and proxy-assessments [61].

Key points for assessing PD in PwID are summarized in Table 1.

Table 1: Key Points for Assessing PD in PwID

\begin{tabular}{|ll|}
\hline - & flexible setting; \\
\hline - & on site assessment (daily life environment of the PwID); \\
\hline - & simple and unambiguous language; \\
\hline - & $\begin{array}{l}\text { multiple-choice/open questions supported by } \\
\text { pictures/symbols; }\end{array}$ \\
\hline - & multi-professional team; \\
\hline - & $\begin{array}{l}\text { combination of self and proxy assessment (source of } \\
\text { information) }\end{array}$ \\
\hline - & use of diagnostic criteria for PwID, such as DC-LD or DM-ID \\
\hline
\end{tabular}

\section{Assessment Tools}

There are many tools that clinicians may use in their practice according to the specific case: self-report or interview tools can be excellent choices to assess personal suffering in subjects with good psychological insight and communication skill, whereas instruments based on proxy information have more value for behavioural equivalents of symptoms and for gathering more reliable information. Although several studies on the psychometric characteristics and clinical utility of diagnostic instruments for children and adults have been published, problems of reliability and validity remain for the majority of them.
The mapping of the literature allowed to identify the diagnostic tools most frequently used in clinical and research setting, which are listed in Table 2 and described hereunder.

Table 2: Most Common Assessment Tools for PD in PwID

\begin{tabular}{|c|c|}
\hline Tool & year \\
\hline \hline PIMRA & 1983 \\
\hline PIMRA-II & 2014 \\
\hline DASH & 1991 \\
\hline DASH-II & 1994 \\
\hline PAS-ADD & 1997 \\
\hline Cha-PAS & 2013 \\
\hline RSMB & 1988 \\
\hline P-AID & 2008 \\
\hline SPAID-G & 2011 \\
\hline ABCL & 2007 \\
\hline BSI & 2003 \\
\hline
\end{tabular}

The 'Psychopathology Instrument for Mentally Retarded Adults (PIMRA)' [62-64] is a structured interview, available both in a self- and other-report form, based on the DSM diagnostic criteria. It has been developed to screen for the presence of psychopathology in individuals with mild and moderate ID. This scale is widely used, so that 31 studies have been published using the PIMRA as a primary measure, whereas others have used the PIMRA as an anchor scale in order to establish the validity of other general measures of psychopathology for PwID. However, although the evidence of its utility in therapeutic planning, in the evaluation of treatment outcomes, and in research settings [65,66], frequent disparities between evaluators have been reported $[25,67,68]$, particularly in case of different cultural background or in absence of training [69]. Moreover, it has been observed that PIMRA may produce false negatives in assessing the presence of $P D$, because of the frequent omission of items involving high linguistic competence or abstract reasoning in people with more severe ID [70]. To address this issue, a revised version of the PIMRA has just been developed (PIMRA-II) and it seems to have good psychometric properties [71].

The DASH-II, which is the revised version of the 'Diagnostic Assessment for the Severely Handicapped (DASH)' [72,73], is largely the most extensively studied scale for the assessment of psychopathology and 
patterns of disordered behaviour in people with severe/profound ID [75]. It evaluates the presence of various key symptoms related to different syndromic clusters, defined by frequency, duration and severity. However, the DASH-II is composed by unbalanced number of items respect to the various psychic dimensions and by the presence of symptomatological and behavioural descriptions that cannot be referred to standardized groups. It has been suggested that this may lead to incorrect diagnostic hypotheses [75].

Another widely used scale is the 'Reiss Screen for Maladaptive Behaviour (RSMB)' [76], that has been recently translated and studied in European Frenchspeaking populations [77]. In this scale items are divided in symptom, nontechnical definition, and a common behavioural example, in order to facilitate the understanding by non-professionals. Evidence shows that RSMB is effective in evaluating specific behaviours, such as aggression, problems in thinking, delusions, fear, hallucinatory behaviours, paranoid tendencies, regressive behaviours, and sleep problems, in a comprehensive psychiatric evaluation without any cross-cultural limitation [78]. The RSMB has been judged as one of the most promising tools for screening depression [79], whereas its autism subscale presented a weak diagnostic utility, so that it is not recommended to diagnose autism in PwID [78].

There may be instances when the examiner wishes to conduct a quick screen for PD in adults, and in these cases the PAS-ADD (Psychiatric Assessment Schedule for Adults with Developmental Disabilities) [80] could be useful. This instrument produces a diagnosis according to ICD-10, and showed reasonable reliability and validity [81, 46, 82]. Moreover, it is available in two other forms: the Mini PAS-ADD [83] and the PAS-ADD Checklist [82]. The PAS-ADD is widely used and supported by an impressive amount of high quality research. However, also the PAS-ADD presents some critical issues, such as the time frame limits for the assessment of psychiatric symptomatology, that do not allow the use of screening-relevant retrospective data [75], or lack of sensitivity for schizophrenic spectrum disorders.

A child and adolescent version of the Mini PAS$A D D$ has recently come out in response to increasing requests concerning the lower age limit for using the original tool. This version, named ChA-PAS, can be used to interview the young person, or an informant, or both together [84].
Another tool worth of being mentioned is the Psychopathology Checklists for Adults with Intellectual Disability (P-AID) that has been designed to identify mental health needs at a high diagnostic level according to the DC-LD. It evaluates 10 psychiatric disorders and 8 types of problematic behaviours, and showed high internal consistency and inter-rater reliability. However, sensitivity and specificity are still to be confirmed [85].

To address the aforementioned limitations of the cited assessment tools, the 'Psychiatric Instrument for the Intellectually Disabled Adult (SPAID) has been recently developed. It includes a general version (SPAID-G) useful to screen for the most important psychopathologic areas of diagnosis. The key features of the SPAID-G are represented by the capability of detecting aggregate symptoms according to a diagnostic orientation, and to identify psychiatric symptoms by the observation of behaviours across the range of severity of ID. It allows a preliminary and useful screening that needs to be followed by the administration of other SPAID tools, representing some area-specific modules for the differential diagnosis. The SPAID-G showed good psychometric properties and is considered as a quick and understandable tool to be used by different professionals even without specific training [75].

Our literature mapping on the instruments used for psychiatric assessment in PwID found some scales not specifically designed for this population. Among them, the 'Adult Behavior Checklist (ABCL)' [86] and the 'Brief Symptom Inventory (BSI)' [87-89] have been particularly studied in the last years.

Obviously, all the scales currently used should be adapted to DSM-5 and more research is clearly warranted.

\section{CONCLUSION}

Up until now, the assessment of PD in PwID is still challenging. Even though in the last years relevant advances have been reached, there are still several issues that have been accurately described in this review. Currently, there is an increasing interest in screening instruments to detect PD in PwID in a quick and accurate way in mental health services in order to provide appropriate care and support for these patients. Although their utility and strengths, the commonly used assessment tools are still affected by some problems of reliability and validity. In this context, 
the more recent developed SPAID seems to be a promising diagnostic tool, allowing individualised assessment in this heterogeneous and variable patient group.

\section{REFERENCES}

[1] Cooper SA, Smiley E, Morrison J, Williamson A, Allan L. Mental ill-health in adults with intellectual disabilities: prevalence and associated factors. $\mathrm{Br} \mathrm{J}$ Psychiatry 2007; 190: 27-35.

http://dx.doi.org/10.1192/bjp.bp.106.022483

[2] Salvador-Carulla L, Rodriguez-Blazquez C, Rodriguez De Molina M, Perez-Marin J, Velazquez R. Hidden psychiatric morbidity in a vocational programme for people with intellectual disability. J Intellectual Disabil Res 2000; 44: 147154.

http://dx.doi.org/10.1046/j.1365-2788.2000.00272.x

[3] Smiley E, Cooper S-A, Finlayson J, et al. The incidence and predictors of mental ill-health in adults with intellectual disabilities. Prospective study. Br J Psychiatry 2007; 191: 313-319.

http://dx.doi.org/10.1192/bjp.bp.106.031104

[4] Ansseau M, Dierick M, Buntinkx F, Cnockaert P, De Smedt J, Van Den Haute M, Vander Mijnsbrugge D. High prevalence of mental disorders in primary care. J Affect Disord 2004; 78: 49-55.

http://dx.doi.org/10.1016/S0165-0327(02)00219-7

[5] Luckasson R, Borthwick-Duffy S, Buntinx WHE, et al. Mental retardation: Definition, classification, and systems of supports (10th ed.).The AAMR AD HOC Committee on Terminology and Classification Washington DC US, Washington, DC, American Association on Mental Retardation; 2002.

[6] Holland AJ, Koot HM. Mental health and intellectual disability: an international perspective. J Intellectual Disabil Res 1998; 42(6): 505-12.

http://dx.doi.org/10.1046/j.1365-2788.1998.4260505.x

[7] Smiley E. Epidemiology of mental health problems in adults with learning disability: An update. Adv Psychiatric Treat 2005; 11: 214-222.

http://dx.doi.org/10.1192/apt.11.3.214

[8] Reiss S, Levtan GW, Szyszko J. Emotional disturbance and mental retardation: Diagnostic overshadowing. Am J Ment Defic 1982; 86: 567-574.

[9] Reiss S, Szyszko J. Diagnostic overshadowing and professional experience with mentally retarded people. Am J Ment Defic 1983; 8: 396-402.

[10] O'Brien G,Yule W. Behavioural Phenotypes. Cambridge: Cambridge University Press; 1995.

[11] Griffiths DM, Gardner WI. The integrated biopsychosocial approach to challenging behaviours. In Griffiths DM, Stavrakaki C, Summers J. Dual diagnosis: An introduction to the mental health needs of persons with developmental disabilities. Sudbury. Habilitative Mental Health Resource Network, 2002; p. 81-114

[12] Werner S, Stawski M. Mental health: knowledge, attitudes and training of professionals on dual diagnosis of intellectual disability and psychiatric disorder. J Intellectual Disabil Res 2012; 56(3): 291-304.

http://dx.doi.org/10.1111/j.1365-2788.2011.01429.x

[13] Oliver MN, Leimkuhl TT, Skillman GD. Training needs, work related stressors, and job satisfaction of community staff supporting adults with mental retardation: implications for ensuring optimal support quality. The NADD Bulletin 2003; 6 . Available at: http: //www.thenadd.org/cgi-bin/checkmember.

[14] Costello $H$, Bouras $N$, Davis $H$. The role of training in improving community care staff awareness of mental health problems in people with intellectual disabilities. J Appl Res Intellect Disabil 2007; 20: 228-35.

http://dx.doi.org/10.1111/j.1468-3148.2006.00320.x

[15] Kwok HW, Chui EM. A survey on mental health care for adults with intellectual disabilities in Asia. J Intellectual Disabil Res 2008; 52(11): 996-1002. http://dx.doi.org/10.1111/j.1365-2788.2008.01054.x

[16] Jeevanandam L. Perspectives of intellectual disability in Asia: epidemiology, policy, and services for children and adults. Curr Opin Psychiatry 2009; 22(5): 462-8. http://dx.doi.org/10.1097/YCO.0b013e32832ec056

[17] Rutter D, Francis J, Coren E, Fisher M. SCIE Systematic Research Reviews: Guidelines. Social Care Institute for Excellence, 2nd ed. London; 2010.

[18] White MJ, Nichols CN, Cook RS, Spengler PM, Walker BS Look KK. Diagnostic overshadowing and mental retardation: a meta-analysis. Am J Ment Retard 1995; 100(3): 293-8.

[19] Deb S, Thomas M, Bright C. Mental disorder in adults with intellectual disability. 2: The rate of behaviour disorders among a community-based population aged between 16 and 64 years. J Intellectual Disabil Res 2001; 45(6): 506-14. http://dx.doi.org/10.1046/j.1365-2788.2001.00373.x

[20] Jopp DA, Keys CB. Diagnostic overshadowing reviewed and reconsidered. Am J Ment Retard 2001; 106(5): 416-33. http://dx.doi.org/10.1352/08958017(2001)106<0416:DORAR >2.0.CO;2

[21] Sovner R. Limiting factors in the use of DSM-III criteria with mentally ill/ mentally retarded persons. Psychopharmacol Bull 1986; 24: 1055-1059.

[22] Sovner R, DesNoyers Hurley A. Four factors affecting the diagnosis of psychiatric disorders in mentally retarded persons. Psychiatric Aspects of Mental Retardation Reviews 1986; 5: 45-48.

[23] Bouras N, Moss S, Kiernan C. The relationship between challenging behavior and psychiatric disorders in people with severe intellectual disabilities. In Bouras N. Psychiatric and behavioral disorders in mental retardation. Cambridge University, Cambridge 1999; p. 38-48.

[24] Cooper SA, Melville CA, Einfeld SL. Psychiatric diagnosis, intellectual disabilities and Diagnostic Criteria for Psychiatric Disorders for use with Adults with Learning Disabilities/Mental Retardation (DC-LD). J Intellectual Disabil Res 2003; 47: 3-15. http://dx.doi.org/10.1046/j.1365-2788.47.s1.2.x

[25] Sturmey P, Ley T. The psychopathology instrument for mentally retarded adults: Internal consistencies and relationship to behaviour problems. Br J Psychiatry 1990; 156: $428-430$.

http://dx.doi.org/10.1192/bjp.156.3.428

[26] Moss S, Emerson E, Kiernan CK, Turner S, Hatton C, Alborz, A. Psychiatric symptoms in adults with learning disability and challenging behavior. Br J Psychiatry 2000; 177: 452-456. http://dx.doi.org/10.1192/bip.177.5.452

[27] Costello H, Bouras N. Assessment of mental health problems in people with intellectual disabilities. Isrl J Psychiatry Relat Sci 2006; 43(4): 241-51.

[28] Emerson E, Moss S, Kiernan CK. The relationship between challenging behavior and psychiatric disorders in people with severe intellectual disabilities.In Bouras N. Psychiatric and behavioral disorders in mental retardation. Cambridge, Cambridge University 1999; 38-48.

[29] Felce D, Kerr M, Hastings RP. A general practice-based study of the relationship between indicators of mental illness and challenging behaviour among adults with intellectual disabilities. J Intellectual Disabil Res 2009; 53(3): 243-254. http://dx.doi.org/10.1111/j.1365-2788.2008.01131.x

[30] Hemmings CP, Gravestock S, Pickard M, Bouras N. Psychiatric symptoms and problem behaviours in people with 
intellectual disabilities. J Intellectual Disabil Res 2006; 50(4): 269-276.

http://dx.doi.org/10.1111/j.1365-2788.2006.00827.x

[31] Kishore MT, Nizamie SH, Nizamie A. The behavioural profile of psychiatric disorders in persons with intellectual disability. J Intellectual Disabil Res 2005; 49(11): 852-857. http://dx.doi.org/10.1111/j.1365-2788.2005.00763.x

[32] Rojahn J, Matson JL, Naglieri JA, Mayville E. Relationships between psychiatric conditions and behavior problems among adults with mental retardation. Am J Ment Retard 2004; 109(1): 21-33.

http://dx.doi.org/10.1352/08958017(2004)109<21:RBPCAB>2.0.CO;2

[33] Hurley A. Mood disorders in intellectual disability. Curr Opin Psychiatry 2006; 19: 465-469. http://dx.doi.org/10.1097/01.yco.0000238471.84206.0a

[34] Charlot L. Use of behavioral equivalents for symptoms of mood disorders. In Sturmey P. Mood disorders in people with mental retardation. Kyngston, New York: NADD Press 2005: p-17-45.

[35] Tsiouris JA, Mann R, Patti PJ, Sturmey P. Challenging behaviors should not be considered as depressive equivalents in individuals with intellectual disability", J Intellectual Disabil Res 2003; 47: 14-21. http://dx.doi.org/10.1046/j.1365-2788.2003.00456.x

[36] Rojahn J, Meier LJ. Epidemiology of Mental Illness and Maladaptive Behavior in Intellectual Disabilities. In Robert $\mathrm{MH}$. International Review of Research in Mental Retardation. Elsevier, Amsterdam: Elsevier; 2009; 38: 239-287. http://dx.doi.org/10.1016/s0074-7750(08)38009-4

[37] Clarke DM, McKenzie DP. A caution on the use of cut-points applied to screening instruments or diagnostic criteria. J Psychiatr Res 1994; 28(2): 185-8.

http://dx.doi.org/10.1016/0022-3956(94)90029-9

[38] Cooper SA, Bailey NM. Psychiatric disorders among adults with learning disabilities - prevalence and relationship to ability level. Ir J Psychol Med 2001; 18: 45-53.

[39] American Psychiatric Association. Diagnostic and statistical manual of mental disorders ( $4^{\text {th }}$ ed. text. rev.). Washington DC: Author 2000.

[40] American Psychiatric Association. Diagnostic and statistical manual of mental disorders (5th ed.). Washington DC: Author 2013

[41] World Health Organization. The ICD-10 Classification of mental and behavioural disorders - diagnostic criteria for research. Geneva: World Health Organization; 1993.

[42] Cain NN, Davidson PW, Burhan AM, et al. Identifying bipolar disorders in individuals with intellectual disability. J Intellectual Disabil Res 2003; 47(1): 31-38.

http://dx.doi.org/10.1046/j.1365-2788.2003.00458.x

[43] Clarke DJ, Gomez GA. Utility of modified DCR-10 criteria in the diagnosis of depression associated with intellectual disability. J Intellectual Disabil Res 1999; 43(5): 413-420. http://dx.doi.org/10.1046/j.1365-2788.1999.043005413.x

[44] Davis JP, Judd FK, Herrman H. Depression in adults with intellectual disability. Part 2: A pilot study. Austr N Z JPsychiatry 1997; 31(2): 243-251.

http://dx.doi.org/10.3109/00048679709073827

[45] Marston GM, Perry DW, Roy A. Manifestations of depression in people with intellectual disability. J Intellectual Disabil Res 1997; 41(6): 476-480.

http://dx.doi.org/10.1111/j.1365-2788.1997.tb00739.x

[46] Moss S, Ibbotson B, Prosser H, Goldberg D, Patel P, Simpson, N. Validity of the PAS-ADD for detecting psychiatric symptoms in adults with learning disability (mental retardation). Soc Psychiatry Psychiatr Epidemiol 1997; 32(6): 344-354.

http://dx.doi.org/10.1007/BF00805440
[47] Ross E, Oliver C. The assessment of mood in adults who have severe or profound mental retardation. Clin Psychol Rev 2003; 23(2): 225-245. http://dx.doi.org/10.1016/S0272-7358(02)00202-7

[48] Szymanski LS, King B, Goldberg B, Reid AH, Tonge BJ, Cain $\mathrm{N}$. Diagnosis of mental disorders in people with mental retardation, Ohio State University, Nisonger Center, Columbus OH; 1998.

[49] Royal College of Psychiatrists. Diagnostic Criteria for Psychiatric Disorders for use with Adults with Learning Disabilities/ Mental Retardation (DC-LD). Gaskell, Londra; 2001.

[50] Fletcher R, Loschen E, Stavrakaki C, First M. Diagnostic Manual -- Intellectual Disability (DM-ID): A Textbook of Diagnosis of Mental Disorders in Persons with Intellectual Disability. Kingston, New York: NADD Press 2007.

[51] Fletcher RJ, Havercamp SM, Ruedrich SL, Benson BA, Barnhill LJ., Cooper SA, Stavrakaki C. Clinical usefulness of the diagnostic manual-intellectual disability for mental disorders in persons with intellectual disability: results from a brief field survey. J Clin Psychiatry 2009; 70(7): 967-974. http://dx.doi.org/10.4088/JCP.08m04429

[52] O'Brien G. The classification of problem behaviour in Diagnostic Criteria for Psychiatric Disorders for Use with Adults with Learning Disabilities/Mental Retardation (DC-LD). J Intellectual Disabil Res 2003; 47(1): 32-37. http://dx.doi.org/10.1046/j.1365-2788.47.s1.39.x

[53] Heal LW, Sigelman CK. Response biases in interviews of individuals with limited mental ability. J Intellectual Disabil Res 1995; 39(4): 331-40. http://dx.doi.org/10.1111/j.1365-2788.1995.tb00525.x

[54] Moss S, Prosser H, Ibbotson B, Goldberg D. Respondent and informant accounts of psychiatric symptoms in a sample of patients with learning disability. J Intellectual Disabil Res 1996; 40: 457-465. http://dx.doi.org/10.1111/j.1365-2788.1996.tb00652.x

[55] Bramston P, Fogarty G. The assessment of emotional distress experienced by people with an intellectual disability: a study of different methodologies. Res Dev Disabil 2000; 21(6): $487-500$ http://dx.doi.org/10.1016/S0891-4222(00)00054-8

[56] Mikkelsen EJ, McKenna L. Psychopharmacologic algorithms for adults with developmental disabilities and difficult-todiagnose behavioral disorders. Psychiatric Ann 1999; 29: 302-314.

http://dx.doi.org/10.3928/0048-5713-19990501-11

[57] Pickard AS, Knight SJ. Proxy evaluation of health-related quality of life: a conceptual framework for understanding multiple proxy perspectives. Med Care 2005; 43: 493-499. http://dx.doi.org/10.1097/01.mlr.0000160419.27642.a8

[58] Petry K, Maes B, Vlaskamp C. Measuring the quality of life of people with profound multiple disabilities using the QOLPMD: first results. Res Dev Disabil 2009; 30(6): 1394-405. http://dx.doi.org/10.1016/j.ridd.2009.06.007

[59] Kazdin AE, Petti TA. Self-report and interview measures of childhood and adolescent depression. J Child Psychol Psychiatry 1982; 23(4): 437-57. http://dx.doi.org/10.1111/j.1469-7610.1982.tb00089.x

[60] Benson BA, Ivins J. Anger, depression and self-concept in adults with mental retardation. J Intellectual Disabil Res 1992; 36(2): 169-75.

http://dx.doi.org/10.1111/j.1365-2788.1992.tb00492.x

[61] Verdugo MA, Schalock RL, Keith KD, Stancliffe RJ. Quality of life and its measurement: important principles and guidelines. J Intellectual Disabil Res 2005; 49: 707-717. http://dx.doi.org/10.1111/j.1365-2788.2005.00739.x

[62] Kazdin AE, Matson JL, Senatore $V$. Assessment of depression in mentally retarded adults. Am J Psychiatry 1983; 140: 1040-1043 http://dx.doi.org/10.1176/ajp.140.8.1040 
[63] Matson JL, Kazdin AE, Senatore V. Psychometric properties of the Psychopathology Instrument for Mentally Retarded Adults. Appl Res Ment Retard 1984; 5: 81-89. http://dx.doi.org/10.1016/S0270-3092(84)80021-1

[64] Matson JL, Belva BC, Hattier MA, Matson ML. Scaling methods to measure psychopathology in persons with intellectual disabilities. Research In Developmental Disabilities.2012; 33 (2): 549-62. http://dx.doi.org/10.1016/.iridd.2011.10.023

[65] Swiezy NB, Matson JL, Kirkpatrick-Sanchez S, Williams DE. A criterion validity study of the schizophrenia subscale of the Psychopathology Instrument for Mentally Retarded Adults (PIMRA). Res Dev Disabil 1995; 16: 75-80. http://dx.doi.org/10.1016/0891-4222(94)00027-7

[66] La Malfa G, Bertelli M, Conte M, Salvini R, Cabras PL. Use of risperidone in the treatment of aggressive behaviour in mentally retarded patients. Minerva Medica 2001; 42: 119124.

[67] Linaker O. DSM-III diagnosis compared with factor structure of the Psychopathology Instrument for Mentally Retarded Adults (PIMRA) in an institutionalized, mostly severely retarded population. Res Dev Disabil 1991; 12: 143-153. http://dx.doi.org/10.1016/0891-4222(91)90003-B

[68] Minner A, Savelsberg PM, Hoogduin K. A Dutch version of the Psychopathology Instrument for Mentally Retarded Adults (PIMRA). Res Dev Disabil 1994; 15: 264-278.

[69] Havercamp SM, Reiss S. Composite versus multiple-rating scales in the assessment of psychopathology in people with mental retardation. J Intellectual Disabil Res 1996; 40: 176179.

http://dx.doi.org/10.1111/j.1365-2788.1996.tb00619.x

[70] La Malfa G, Notarelli A, Hardoy MC, Bertelli M, Cabras PL. Psychopathology and mental retardation: An Italian epidemiological study using the PIMRA. Res Dev Disabil 1997; 18: 179-184.

http://dx.doi.org/10.1016/S0891-4222(97)00002-4

[71] Belva BC, Matson JL. Examining the psychometrics of the Psychopathology Inventory for Mentally Retarded Adults-II for individuals with mild and moderate intellectual disabilities. Res Dev Disabil 2014; 30 (36C): 291-302.

[72] Matson JL, Coe DA, Gardner WI, Sovner R. A factor analytic study of the Diagnostic Assessment for the Severely Handicapped scale. J N Ment Disabil 1991; 179: 553-557. http://dx.doi.org/10.1097/00005053-199109000-00006

[73] Matson JL. Diagnostic Assessment for the Severely Handicapped-II. Baton Rouge, LA: Scientific Publishers; 1994.

[74] Matson JL, Baglio CS, Smiroldo BB, et al. Characteristics of autism as assessed by the Diagnostic Assessment for the Severely Handicapped-II (DASH-II). Res Dev Disabil 1996; 57: 44-52. http://dx.doi.org/10.1016/0891-4222(95)00044-5

[75] Bertelli M, Scuticchio D, Ferrandi A, Lassi S, Mango F, Ciavatta C, Porcelli C, Bianco A, Monchieri S. Reliability and validity of the SPAID-G checklist for detecting psychiatric disorders in adults with intellectual disability. Res Dev Disabil 2012; 33(2): 382-90.

http://dx.doi.org/10.1016/j.ridd.2011.08.020

[76] Reiss S. (1988). The Reiss Screen Test manual Orland Park, IL: International Diagnostic Systems, Inc.
[77] Straccia C, Tassé MJ, Ghisletta P, Barisnikov K. The French version of the Reiss Screen for Maladaptive Behavior: factor structure, point prevalence and associated factors. Res Dev Disabil 2013; 34(11): 4052-4061.

http://dx.doi.org/10.1016/j.ridd.2013.08.034

[78] Kishore MT, Nizamie SH, Nizamie A. Utility of Reiss screen in identifying psychiatric problems in persons with mental retardation. Indian J Psychol Med 2010; 32: 38-41. http://dx.doi.org/10.4103/0253-7176.70531

[79] Hermans $\mathrm{H}$, Evenhuis HM. Characteristics of instruments screening for depression in adults with intellectual disabilities: systematic review. Res Dev Disabil 2010; 31(6): 1109-1120. http://dx.doi.org/10.1016/j.ridd.2010.04.023

[80] Moss S, Patel P, Prosser $\mathrm{H}$ et al. Psychiatric morbidity in older people with moderate and severe learning disability. I: Development and reliability of the patient interview (PASADD). Br J Psychiatry 1993; 163: 471-480. http://dx.doi.org/10.1192/bip.163.4.471

[81] Costello $\mathrm{H}$, Moss $\mathrm{S}$, Prosser $\mathrm{H}$, Hatton $\mathrm{C}$. Reliability of the ICD 10 version of the Psychiatric Assessment Schedule for Adults with Developmental Disability (PAS-ADD). Soc Psychiatry Psychiatr Epidemiol 1997; 32(6): 339-43. http://dx.doi.org/10.1007/BF00805439

[82] Moss $\mathrm{S}$, Prosser $\mathrm{H}$, Costello $\mathrm{H}$, et al. Reliability and validity of the PAS-ADD checklist for detecting psychiatric disorders in adults with intellectual disability. J Intellectual Disabil Res 1998; 42: 173-183. http://dx.doi.org/10.1046/j.1365-2788.1998.00116.x

[83] Prosser H, Moss S, Costello H, Simpson N, Patel P, Rowe S. Reliability and validity of the Mini-PAS-ADD for assessing psychiatric disorders in adults with intellectual disability. J Intellectual Disabil Res 1998; 42: 264-272. http://dx.doi.org/10.1046/j.1365-2788.1998.00146.x

[84] Moss S, Friedlander R, Lee P. The ChA-PAS Interview Handbook and Clinical Interview. Pavilion Publishing and Media: 2013.

[85] Hove O, Havik OE. Psychometric properties of Psychopathology checklists for Adults with Intellectual Disability (P-AID) on a community sample of adults with intellectual disability. Res Dev Disabil 2008; 29: 467-482. http://dx.doi.org/10.1016/j.ridd.2007.09.002

[86] Tenneij $\mathrm{NH}$, Koot HM. A preliminary investigation into the utility of the adult behavior checklist in the assessment of psychopathology in people with low IQ. J Appl Res Intellectual Disabil Res 2007; 40: 198-207. http://dx.doi.org/10.1111/j.1468-3148.2007.00383.x

[87] Kellett S, Beail N, Newman DW, Frankish P. Utility of the brief symptom inventory in the assessment of psychological distress. J Appl Res Intellect Disabil 2003; 16: 127-134. http://dx.doi.org/10.1046/j.1468-3148.2003.00152.x

[88] Kellett S, Beail N, Newman DW, Hawes A. The factor structure of the brief symptom inventory: Intellectual disability evidence. Clin Psychol Psychother 2004; 11: 275-281. http://dx.doi.org/10.1002/cpp.410

[89] Wieland J, Wardenaar KJ, Fontein E, Zitman FG. Utility of the Brief Symptom Inventory (BSI) in psychiatric outpatients with intellectual disabilities. J Intellectual Disabil Res 2012; 56(9): 843-53.

http://dx.doi.org/10.1111/j.1365-2788.2011.01440.x

(C) 2015 Bertelli et al.; Licensee Lifescience Global.

This is an open access article licensed under the terms of the Creative Commons Attribution Non-Commercial License (http://creativecommons.org/licenses/by-nc/3.0/) which permits unrestricted, non-commercial use, distribution and reproduction in any medium, provided the work is properly cited. 